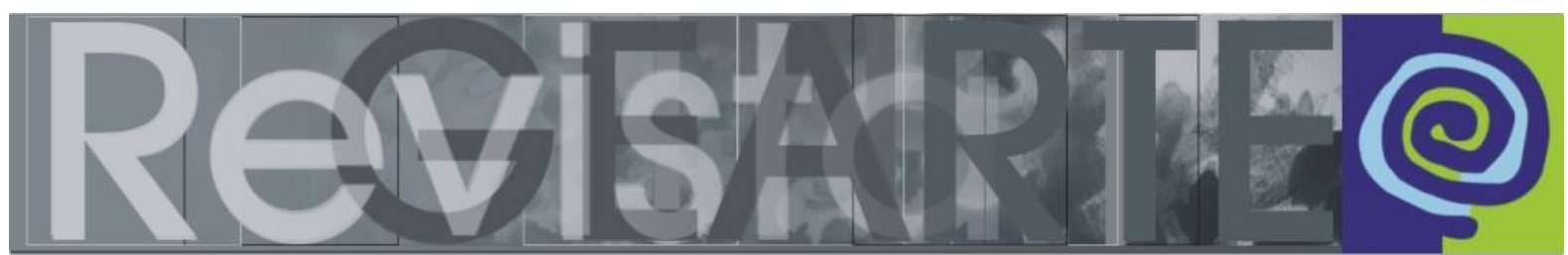

ISSN 2357-9854

\title{
Corpo (i)ética: arte, corpo e produção de sentidos na educação de jovens e adultos (EJA)
}

Fernando Yonezawa (Universidade Federal do Espírito Santo -UFES, Vitória/ ES, Brasil)

Márcia Cuevas (Universidade Federal do Espírito Santo -UFES, Vitória/ ES, Brasil)

RESUMO - Corpo (i)ética: arte, corpo e produção de sentidos na educação de jovens e adultos (EJA) - Este texto pretende apresentar a experiência de intervenção junto a uma escola municipal de jovens e adultos de Vitória (ES), onde realizamos oficinas corporais-artísticas com o intuito de produzir sentidos insuspeitos no processo de aprendizagem. Utilizando-nos dos conceitos filosóficos de Deleuze e Guattari e de recursos como instalações artísticas interativas, procuramos produzir uma aprendizagem que interviesse no campo afetivo dos estudantes, de modo a tocarmos em suas concepções e modos de sentir. Destacamos aqui o caráter político, ético e estético destas intervenções, na medida em que abordaram temas como a misoginia e ecologia (política), movimentando os valores nos corpos (ética), a partir da ação sobre a sensibilidade (estética).

PALAVRAS-CHAVE:

Arte. Corpo. Sentido. Aprendizagem. EJA.

RESUMEN - Cuerpo (i) la ética: el arte, el cuerpo y la producción de sentido en la educación de jóvenes y adultos (EJA) - Este texto tiene la intención de presentar la experiencia en una intervención con jóvenes y adultos de una escuela municipal, donde llevamos a cabo talleres corporales-artísticos con el fin de producir sentidos insospechados en el proceso de aprendizaje. Utilizando los conceptos filosóficos de Deleuze y Guattari y recursos tales como, instalaciones de arte interactivas, buscamos producir un aprendizaje para intervenir en el campo afectivo de los estudiantes, en sus concepciones y formas de sentir. Destacamos el carácter político, ético y estético de estas intervenciones, puesto que fueron tratados temas como misoginia y ecología (política), poniendo en movimiento los valores de los cuerpos (ética), a partir de acciones sobre la sensibilidad (estética).

PALABRAS CLAVE:

Arte. Cuerpo. Sentido. Aprendizaje. EJA.

\section{Desde que lugar falamos? Quais as nossas questões?}

Desde 2014, como pesquisadores em Psicologia Institucional ${ }^{1}$ e vinculados ao Fórum de Educação de Jovens e Adultos do Espírito Santo, realizamos intervenções em uma Escola Municipal de Ensino Fundamental de Jovens e Adultos da cidade de Vitória, experimentado a construção de grupalidades diversificadas, que reúnem estudantes e educadores da escola, pesquisadores de pós-graduação e iniciação

1 Pesquisa amparada pela CAPES e pela Fundação de Amparo à Pesquisa e Inovação do Espírito Santo. 
científica e gestores da EJA em torno do desafio de realizar práticas educacionais transformadoras, que superem práticas históricas de machismo, homofobia, homogeneização dos corpos, entre tantas outras manifestações que não afirmam relações educacionais potentes.

O projeto político pedagógico e as ações desta escola assumem um caráter claramente militante, objetivando levar o direito à educação àqueles que o tiveram negado pelo sistema educacional tradicional, de modo a incluir as diversas minorias. Para isso, a escola se pulverizou por turmas espalhadas por diferentes territórios da cidade, onde prima por uma inclusão educacional que possibilite a interação das mais distintas especificidades: existem salas localizadas dentro de uma associação de material reciclável, ou dentro de um centro de convivência da terceira idade, onde estudam adolescentes juntos com idosos de 80 anos, jovens em situação de conflito com a lei e mulheres transexuais. Tomam a educação popular freireana como sua norteadora e constantemente recebem pesquisadores de diferentes áreas para atuarem em seu cotidiano.

Durante estes anos de pesquisa, temos nos orientado pela perspectiva da pesquisa-intervenção, pois nesta modalidade afirmamos o caráter político inerente a toda investigação. Segundo Paulon e Romagnoli (2010, p.92), na pesquisaintervenção se assume o compromisso social do pesquisador, que investiga implicado com os efeitos não-neutros de sua atuação, prescindindo da dicotomia sujeito-objeto. Dentro desta perspectiva de pesquisa, escolhemos a cartografia como metodologia de atuação. Esta compreende a pesquisa como ação num campo de imanência, onde distintas forças (culturais, midiáticas, biológicas, afetivas etc.) compõem uma realidade singular. Deleuze (1997, p.75), diz que cartografar é criar uma listagem de afetos experimentados em um deslocamento, o qual revela os impasses e aberturas de uma realidade. Ultrapassando ainda a dicotomia objetividade $x$ subjetividade, a cartografia inclui os afetos que passam, tanto pelos sujeitos pesquisados, como pelo próprio pesquisador. Destarte, Barros e Barros (2013, p.377) lembram que a cartografia porta uma dimensão clínica, pois ela implica ações capazes de transformar o campo de forças em que é realizada. Logo, a cartografia não retrata a realidade, mas a produz, enquanto nela age. 
Por isso, nossa pesquisa nesta escola tem se realizado a partir da participação ativa em reuniões de gestão e de formação docente, aulas e seminários especiais, planejamentos de atividades pedagógicas e formações, militância e grupos de estudo, buscando deflagrar movimentos de produção de potência e de resistência diante do instituído ossificado.

No ano de 2016 experimentamos, junto a educadores e estudantes, desafios múltiplos, quando se assume o compromisso de produzir práticas educacionais que rompam com a verticalização do saber e a desqualificação dos distintos modos de viver e conhecer. Entre estes desafios, trabalhar com os jovens temas que peçam um deslocamento dos conteúdos disciplinares comuns foi um dos mais presentes. Com o intento de produzir sujeitos críticos, a escola aborda temas políticos, como os problemas ambientais e o respeito à diversidade sexual. Sempre que propúnhamos discutir tais questões sentíamos como se aparecesse um muro de indiferença ou rechaço entre educadores e pesquisadores de um lado e, de outro, os estudantes.

Para os educadores da escola, os estudantes jovens viriam muito marcados pelos ranços da escola tradicional conteudista, o que explicaria sua postura de rejeição a temas políticos. Consideramos, ademais, que a produção de modos de vida contemporânea, caracterizada pelo grande foco no consumo, pela valorização narcísica da imagem, pelo esvaziamento dos espaços públicos, pelo ódio à diferença, pela escatologia nas relações amorosas e pelo niilismo - a concepção de que na vida não há valores potentes ou de que seu valor supremo e final se encontra em um único valor hegemônico atual -, também constitui o arranjo do fechamento afetivo dos estudantes.

Conforme Guattari (1999, p.8), é a relação da subjetividade com seu ambiente de cultura, "sua exterioridade - social, animal, vegetal, cósmica - que se encontra assim comprometida numa espécie de movimento geral de implosão e infantilização regressiva". Portanto, é todo o meio onde somos produzidos que está poluído por linhas sufocantes e não apenas uma classe social, ou esfera ambiental; há que se problematizar também uma ecologia afetiva. 
Nesta escola os educadores trabalham em dupla, procurando transversalizar seus conteúdos. Semanalmente acompanhando a dupla de Ciências e Artes em uma das turmas, víamos os estudantes com idades entre 16 a 19 anos sempre se mostrado extremamente desinteressados, ainda que os educadores se fizessem afetuosos, preocupados em dialogar, convidando-os a compor a aula com elementos de suas vidas. Em uma aula, tocamos no tema da violência contra a mulher, levando a informação de que o Espírito Santo é o estado líder em assassinatos a mulheres e que muitos destes acontecem por conta de ciúmes dos homens pelas companheiras. Entre os estudantes, alguns se mostravam indiferentes, uns mexendo em seus celulares, outro cortando os pelos da perna com uma tesoura; ou então, seus discursos revelavam a naturalização do uso da violência para situações de conflito amoroso.

\section{[...] mas, se a mulher olha para outro cara, tem que bater mesmo! [...] se ela traiu merece morrer mesmo! \\ (ESTUDANTES DA ESCOLA, 2016).}

Sentíamo-nos num terrível impasse de diversas ordens: afetivo, pedagógico, político, ético... víamos que as boas intensões da educação popular, baseada em dialogismo, democracia e inclusão do universo existencial dos estudantes não bastavam para garantir a produção de pensares engajados e sensíveis. De fato, não se tratava de julgar a posição dos estudantes e impor-lhes outro modo de pensar supostamente mais ético; tampouco parecia plausível sermos espontaneístas, crendo na suficiência da retirada o autoritarismo do educador para que os estudantes se mostrassem interessados.

\footnotetext{
O que nos incomodava era que, renunciando ao juízo, tínhamos a impressão de nos privarmos de qualquer meio para estabelecer diferenças entre existentes, entre modos de existência, como se a partir daí tudo se equivalesse (DELEUZE, 1997, p. 153).
}

Seria ingênuo confiar que não termos temas planejados tornaria a aula mais democrática e pior seria ignorar que existam temas urgentemente problemáticos a serem levados para a sala de aula. Ora, Deleuze (2006, p.210) diz que aprender algo implica em enfrentar um campo problemático, forçar o pensamento a pensar. Algo só é aprendido sob diversas tonalidades afetivas, envolvendo a sensibilidade e a experiência do encontro do corpo com os afetos da ideia em questão. "Mas, em sua 
primeira característica, e sob qualquer tonalidade, ele só pode ser sentido." (DELEUZE, 2006, p.203) O encontro do aprendiz com uma ideia sempre é um processo tenso, em que a sensibilidade de seu corpo se afeta de modo dissonante com os pontos singulares da ideia. Aí, a aprendizagem não é mais recognição, porque se dá como produção de um novo sentido. Aprender implica, pois, em desconfortar os afetos, pensar o impensado: aprender é sentir de um novo modo.

Assim, tomando o desafio de produzir algum estremecimento na sensibilidade de estudantes e educadores, nossa pesquisa-intervenção focada na relação entre arte, corpo e produção de sentido na educação, ancorada em conceitos filosóficos de Deleuze e Guattari, apostou em realizar experimentações corporais-artísticas nos espaços de aula e seminários da escola no decorrer do ano escolar. Neste artigo colocamos em análise as experimentações e produções vividas e compartilhadas no decorrer de uma oficina realizada no seminário que objetivava deflagrar problematizações e sensibilizações em torno da misoginia.

\section{Penetrar a violência da arte: aprendizagem afetiva}

Em 2016 a escola realizou três seminários temáticos, que abordaram a diversidade sexual, o lugar social da mulher e a cultura afro-brasileira. Nestes seminários foram oferecidas oficinas, rodas de conversa, palestras e manifestações culturais, que intentam reunir estudantes, educadores e comunidade em geral em torno de questões presentes no cotidiano de todos, de forma a promover deslocamentos das sensibilidades.

No seminário dedicado à mulher, a programação, construída de forma coletiva, pretendia colocar a comunidade escolar diante da violência contra a mulher para deflagrar reflexões ativadoras acerca do modo como temos tratado "nossas mulheres". Diante desse desafio, preparamos uma experimentação para estremecer a as sensibilidades dos jovens, abalar sua postura de indiferença ou reiteração da violência.

Inspirados na noção de Hélio Oiticica (1962, p.19 e 8) de que "já não quer o sujeito (espectador) resolver a sua contradição em relação ao objeto pela pura 
contemplação" e, ainda, na sua "tomada de consciência do espaço como elemento totalmente ativo", criamos uma instalação artística com duas fases: uma primeira cabana cúbica, escura e com pouco mais de 1,65m de altura, feita com plástico preto idêntico ao de saco de lixo, em cujas laterais internas foram coladas fotos de mulheres deformadas por espancamentos e queimaduras. Junto dessa exposição fotográfica colamos frases dos estudantes da escola, colhidas das discussões realizadas em aula:

[...] mulher tem que apanhar mesmo..
Bato na barriga para não deixar marca
Mulher prendada faz tudo em casa
Mulher direita não sai de casa
Mulher é proibida de trabalhar
Bela rejeitada de do lar
Mulher direita tem que casar e ter filhos
Mulher tem que fazer tudo para o homem
Mulher boa é aquela que obedece calada
Mulher com roupa curta merece ser estuprada
Mulher de mini saia é vagabunda
Mulher que gosta de mulher não é mulher
Mulher prendada faz tudo em casa
Serviço de casa tem que ser para as mulheres
Mulher que gosta de mulher não é mulher
(ESTUDANTES DA ESCOLA, 2016).

Essas frases impressas foram ainda expostas em áudio, gravado com vozes de professores homens, combinadas com os gritos e gemidos femininos angustiantes da obra Visage de Luciano Berio.

Geminada a esta cabana, erguemos um quadrado, aberto em cima e de um dos lados, feito com tecido azul anil, nos quais havia fotos de mulheres de diferentes classes sociais e profissões, lavando roupas no rio, analisando um tubo de ensaio, trabalhando em escritório, cozinhando; ou seja, buscamos imagens de distintas mulheres ativas trabalhando, fazendo a vida. Junto a esta exposição, reunimos matérias de jornais locais que comunicavam ações, governamentais ou não, em torno do tratamento a mulheres capixabas violentadas. Finalmente, pusemos papéis coloridos picados, flores e uma roda de cadeiras, tapetes, almofadas para que, depois da experiência, pudéssemos ouvir os participantes.

$\mathrm{Na}$ entrada da sala onde instalamos esta cabine de sensações colamos um cartaz vermelho escrito com tinta branca: "Como queremos tratar nossas mulheres?" 
Como Oiticica (1962, p.11), queríamos que este 'penetrável' pudesse transformar em não-imediato o que há de imediato na vivência cotidiana. Mas, diferentemente do artista, não visávamos uma pureza da arte, desvinculando-a de uma tarefa política; afinal, a arte sempre faz política à sua maneira, ainda que alterando o regime de relação com a cor, como faz Oiticica. Nosso trabalho se situa na passagem de linguagens, numa zona transitória, que tende à potência da arte na medida em que implica a transformação de campos de sensibilidade, mas, desta forma, tange também à educação e à clínica.

No dia do seminário, novamente tivemos muitas dificuldades de trazer os estudantes a experimentar a cabine. Muitos estavam arredios, ou desinteressados. Fomos especialmente tentar convencer Andriel $^{2}$, um estudante jovem que se recusava a fazer as atividades em aula ou participar de discussões; sempre com cara de mau, testa franzida, saía constantemente da sala de aula, sem motivo algum que ele próprio expressasse. Era um desafio afetá-lo de algum modo. Então, passamos o braço por cima de seu ombro e chamamos: "Vem cara, vamo lá! Pô, tá sempre com essa cara de bolado!" Resistiu, mas foi, pois enquanto o puxávamos, brincávamos: "Tá com medo né!" Chegando na porta da sala, ficou muito resistente. Perguntou o que tinha ali. Dissemos que ele precisava experimentar sentir para saber. Pedimos que lesse o cartaz da entrada e abrisse o coração. Resistiu, entrou um pouquinho, viu parte das imagens e recuou. Abraçamos de novo e dissemos: "Vamo lá! Entro com você, aguenta um pouco e sente aí." Fomos the explicando um pouco as imagens: falamos da mulher queimada de ácido porque não queria casar, de outra que teve os lábios arrancados por causa do ciúme do marido. Ele também ia perguntando o que havia acontecido com aquelas mulheres. Saiu visivelmente afetado: a carapaça superficial se desmontara e já não estava apenas fechado. Sua expressão era de uma nova dureza: agora, parecia sentir dor em algum órgão interno. Alguma emoção parecia percorrê-lo. Seguiu calado, mas já não quis sair da sala, parecia conectado a tudo o que era dito na roda de discussão, na parte azul da cabine.

2 Os nomes dos estudantes e educadores aqui são fictícios. 
Um sentido havia sido produzido, uma nova sensibilidade nascia. Recusamonos a pensar que nossa insistência em trazer Andriel para a cabine tenha sido uma espécie de autoritarismo sutil, já que feito com brincadeiras. Como dizíamos, o pensamento só se move coagido e isso implica que renunciemos a qualquer fácil dicotomia que julgue a educação pelo seu caráter idílico ou autoritário. Trata-se, aqui, de outra natureza de violência, diferente das violências que problematizamos no seminário. Entendemos que a cabine, com toda sua força de impactar traga uma tensão para o pensamento, a qual não se alivia numa solução verdadeira, ou apenas razoável e cognitiva. Deleuze (2003, p.5) nos ensina que o sentido é produzido pelas misturas de corpos, ainda que não se mantenham dependentes deles. Isso quer dizer que o sentido não é efeito psicológico vindo de um profundo pântano inconsciente, ou de um aparelho cognitivo: o sentido nasce da superfície dos afetos que passam a circular quando do encontro de corpos. Apesar do aparente maniqueísmo, em nossa cabine, não havia apenas duas ideias opostas, com um lado evidenciando o modo violento de tratar a mulher e, outro, o lado bondoso. A textura de saco de lixo, o som angustiante, o teto baixo, o escuro, o azul da segunda parte da cabine, seu lado aberto... cada corpúsculo porta uma força de afetar e seu conjunto constitui séries de elementos expressivos, capazes de violentar o pensamento a partir da sensibilidade. Nossa cabine engolfou os corpos dos estudantes e os tragou para dentro de um mar de afetos, onde

[...] cada termo não tem sentido a não ser por sua posição relativa a todos os outros termos; mas esta posição relativa depende ela própria da posição absoluta de cada termo em função da instância $=x$ determinada como não senso e que circula sem cessar através das séries (DELEUZE, 2003, p. 73).

Dessa forma, os sentidos são gestados fora da pressuposta coerência do pensar. A cabine toda formava um corpo e um meio de desestabilização do senso dominante e, junto com os corpos dos estudantes, produziu sentido, o qual atravessou todos os corpos, posicionando-os em função do deslocamento e não-senso experimentados. O sentido aí não é mais vindo de mentalidades conformadas, consideradas apenas do ponto de vista de uma razão igual em todos (senso comum), afeitas a uma verdade histórica naturalizada (bom senso) e portadoras de uma sensibilidade amortecida, já que apenas respondente, nunca inventiva. Então, vimos a cabine abrir campos de sensibilidade, ao coagir o corpo de Andriel com um 
extravasamento do estado dominante de seus afetos. O sentido produzido na cabine foi artisticamente potente, porque fez transbordar os estados de coisas. Cada sentido, diz Deleuze (2003, p.31), porta o paradoxo de expressar-se infinitamente: a cada expressão, o mesmo sentido se afirma fazendo nascer outro sentido. Por isso, vemos a mudança de expressão de Andriel não como dado interpretável, mas como um efeito múltiplo em si, uma diferença que emerge de seu encontro com a cabine.

Além disso, em outros estudantes, modos de pensar inusitados e marcantes se afirmaram a partir das afetações de seus corpos. Talvez a mais interessante tenha sido: "A questão não é como queremos tratar as mulheres, mas como as mulheres querem ser tratadas." Também um dos estudantes disse acreditar ser preciso oferecer atendimento psicológico para os homens que violentam as mulheres, pois "na prisão eles são punidos, mas entram com ódio e saem com mais ódio ainda e depois vão de novo bater nas mulheres". Vemos aí a potência de produção de diferença que a cabine produzira: força de educar artisticamente, isto é, de transformar o pensamento a partir de campos de sensibilidade.

Uma das estudantes adolescentes que passou pela experimentação disse que nunca deixaria um homem lhe bater, pois se o tentasse, ela bateria de volta. Charles, um dos educadores presentes, tentou dialogar e, nem bem começou a falar, foi cortado pela menina: "É minha opinião, cada um tem a sua opinião, ué." Ora, para Deleuze e Guattari (1992, p.262), a arte é um dos grandes modos do pensamento, junto com a Ciência e a Filosofia e sua tarefa consiste em sair da opinião, emoldurando porções de caos e infinito. Portanto, através da arte, não se trata de conhecer realidades já estabelecidas, senão de produzir mais realidade e dar a encontrar porções de infinito, copos de caos. "Os artistas acrescentam sempre novas variedades ao mundo", pois "o artista é mostrador de afectos, criador de afectos..." (DELEUZE; GUATTARI, 1992, p. 227).

Os autores afirmam que a arte nunca é imitativa e as variedades afectivas que ela apresenta são sempre exteriores à simples opinião. A arte nos dá afectos a serem compartilhados, mas tais afectos não são opiniões; eles são invenções e restituem a dimensão autopoiética e infinitiva da realidade. Esclareçamos: os afectos compreendem os afetos-sentimentos, mas, sendo mais amplos que estes, constituem 
devires que nos colocam numa zona de passagem entre estados sentimentais ou corporais estabelecidos socialmente (DELEUZE, 2002, p. 56): as variedades afectivas da arte deslocam os sensos dados e forçam a dar conta de ondas de potências insuspeitas.

Com efeito, na cabine que montamos, a composição de materiais com suas texturas, seus odores, sons, luminosidades e cores teciam uma pequena porção de afectos devirientes, sentidos devirulentos. Afirmamos que esta cabine produziu uma espécie de violência ao campo afetivo dos estudantes, pois os afectos ali experimentados deram gênese a pensamentos surpreendentes e desconfortou intensamente os corpos calcificados pela repulsão. Obviamente intentávamos sensibilizá-los à gravidade da violência exercida contra a mulher, mas os sentidos ali gerados e os afectos experimentados fugiram do previsível e se expressaram não na forma de conteúdos disciplinares, mas como novas ideias e modulações afetivas. A penetração dos corpos no corpo de afectos da cabine pode ser dito processo artístico porque produziu sentidos paradoxais: violentou os sensos inertes para desnaturalizar a violência. Ainda quando sustentavam suas opiniões sagradas, os corpos não passavam incólumes pelos afectos da cabine.

Juntamente com a geógrafa Massey (2012, p. 201), entendemos que o espaço não seja coordenada pronta, ele é campo de "eventualidade" e também de disputa política. A autora destaca que o espaço não é superfície pré-formada, mas multiplicidade em formação, constituída pelas relações, encontros fortuitos e circulações de corpos. Portanto, a intervenção sobre o espaço é importante porque os efeitos decorrentes são sempre formativos, produtores de corpos e sensibilidades. Em outros termos, é preciso ter em conta que os espaços educam, eles são corpos produtores de outros corpos. Desta maneira, entendemos que a cabine tenha constituído um novo espaço, onde a composição de elementos artísticos pôde tecer corpos insuspeitos.

Já Guattari (1990, p.15), ao discutir os problemas ecológicos, toma os ambientes como agenciamentos complexos de relações entre três diferentes esferas: social, subjetiva e ambiental. Para o autor, estas três esferas são portadoras de inúmeros pontos de "rupturas a-significantes", de onde nascem novos modos de vida. 
Porém, alerta, tais pontos de ruptura não podem proliferar sua fertilidade caso não se construam agenciamentos capazes de Ihes dar suporte e condições fortalecimento. Quer dizer, para que se produzam novos modos de sentir, pensar, lidar com a natureza, com os grupos, com o conhecimento, é preciso que estejamos atentos à produção de novas realidades afetivas, novos espaços formativos, os quais emergem destes pontos de ruptura. Vimos serem abertos estes pontos de ruptura de sentido nos corpos dos estudantes, quando foram imersos no agenciamento de elementos que formava o corpo de afectos da cabine. A cabine construiu um novo ambiente, um novo habitat, para que uma ecologia dos afetos pudesse ser tecida.

A questão, a partir dali, seria dar continuidade, no cotidiano de sala de aula, à multiplicação de diferenças que tais rupturas proporcionaram durante a experimentação no seminário. "Tratar-se-á, de dar conta dessas práticas menos em termos de verdade científica que em função de sua eficácia estético-existencial" (Guattari, 1990, p. 40). Afinal, os campos afetivos formam habitats nos quais os corpos são produzidos. A educação precisa, pois, implicar a ideia de que somente atuando esteticamente nestes ambientes geradores é que se pode produzir diferenças.

\section{Corpo(i)ética: a tessitura de um corpo poético}

Nesta experimentação realizada junto a estudantes de EJA vimos o quanto as aprendizagens mais políticas precisam ser pensadas também de modo estético (artístico) e ético. Consideramos que a aprendizagem conquistada nesta experimentação foi de natureza afetiva e não somente cognitiva. Dizemos que também se tratou de um processo educativo ético justamente porque implicou a sensibilidade dos estudantes e possibilitou mexer com o campo de valores e sentidos norteadores das vidas. Esta aprendizagem se deu a partir da experimentação corporal e teve como efeito a produção (poiética) de sentidos poéticos, cuja potência é sempre de transformar os valores e sensibilidades nos corpos (ética). Denominamos corpo(i)ética este processo de experimentação artística-corporal e de produção de sentidos.

Mesmo tendo visto as sensibilidades se transformarem nesta experimentação, ressaltamos que nossa questão não se esgota: seguimos nos deparando com a 
indiferença, desânimo, negação e desgosto dos estudantes. Afetos que, sem expressar rebeldia, insistem apenas em paralisar as relações. A amargura que sentimos nos estudantes com tudo o que é novo, ou tem caráter artístico, ou então vem questionar suas certezas, é seguramente ranço anacrônico da normatização da escola tradicional, da qual vêm estes jovens. Ademais, concordamos com a análise dos educadores desta escola, de que há muitas barreiras sociais invisíveis colocadas em suas vidas para que não tenham acesso a muitos espaços e bens culturais.

Sabemos, porém, que o modo de produção de vida hegemônico do capitalismo atual é transversal, não recaindo privilegiadamente sobre uma ou outra classe social. O niilismo contemporâneo atravessa a cada sujeito, a cada classe social de um modo específico, sem poupar ninguém. Guattari (1990, p. 32) destaca que uma das questões principais que tangem à produção de uma nova ecologia afetiva é dar conta "da introjeção do poder repressivo por parte dos oprimidos".

Entretanto, a questão é podermos transformar este estado de coisas. Percebemos que, nos corpos dos jovens, há um fechamento para a diferença: a menor diferença já é entendida como oposição. Diante do que estranham, adotam a postura de ignorar ou simplesmente afastar. Não se sentem impelidos a perguntar, ou a questionar. Quando não compreendem algo, ou são intensamente afetados, precisam repelir o que os afeta, porque o não compreender denunciaria uma suposta incompetência ou ignorância, condições absolutamente condenáveis: o não-saber é o crime maior que marca todos os corpos escolarizados. No limite, refugiam-se sob o teto da sagrada opinião pessoal, instituição capitalista pseudo-democrática. Mas, a arte é potente porque começa justamente do não-saber, do não-senso, o terreno criminalizado pela escola tradicional; com a arte profanamos a opinião individual para secretarmos campos de sensibilidades inéditos. Se há motivos para a indiferença, eles não deixam de ser razões e, como tal, precisam ser enlouquecidas pela arte. Consideramos, portanto, que ações de natureza artística sejam importantíssimas, pois constroem um modo de educação afetivo, não porque seja carinhoso e amável, mas porque intervém nas maneiras de sentir, ou seja, lá onde se gesta toda aprendizagem. 
Dialogando com o conceito freireano de "leitura de mundo"3, entendemos que este deva ser mais amplamente entendido, tendo a dimensão estética como imanente a seu fazer, isto é, ler o mundo alienada ou engajadamente, opressora ou compreensivamente é ler, de toda forma, a partir de uma composição de forças afetivas e expressivas.

[...] não esqueçamos a experiência gnosiológica, experiência que tem a ver com o conhecer o mundo [...] somos seres programados para saber, condicionados não determinados, [...] não podemos viver fora desta curiosidade em torno de nós mesmos [...] (FREIRE, 2017).

Em nossas experimentações junto a estudantes e educadores da EJA, podemos destacar que sentidos e aprendizagens singulares emergiram quando se produziram espaços e ambientes afetivos possibilitadores de aberturas para a sensibilidade.

\section{Referências}

BARROS, Letícia; BARROS, Maria Elizabeth. O problema da análise em pesquisa cartográfica. Fractal Revista de Psicologia, Rio de Janeiro, UFF, v. 25, n. 2, p. 373-390, maio/ago. 2013.

BERIO, Luciano. Visage. Disponível em: <https://www.youtube.com/watch?v=j3uv6ZTu9K8>.

DELEUZE, Gilles. Crítica e Clínica. São Paulo: Editora 34, 1997.

DELEUZE, Gilles. Diferença e Repetição. Rio de Janeiro: Graal, 2006.

DELEUZE, Gilles. Espinosa: filosofia prática. São Paulo: Escuta, 2002.

DELEUZE, Gilles. Lógica do sentido. São Paulo: Perspectiva, 2003.

DELEUZE, Gilles; GUATTARI, Félix. O que é a filosofia? Rio de Janeiro: Editora 34, 1992.

FREIRE, P. Ideais, mitos e utopias no final do séc. XX. Conferência ministrada na Universidade de Buenos Aires, Argentina. Disponível em: <https://www.youtube.com/watch?v=eadsgLbBJ8g>. Acesso em: 29 jan. 2017.

GUATTARI, Félix. As Três Ecologias. Campinas: Papirus, 1990.

MASSEY, Doreen. Pelo espaço: uma nova política de espacialidade. Rio de Janeiro: Bertrand Brasil, 2012.

OITICICA, Hélio. Penetráveis. Rio de Janeiro: Centro de Arte Hélio Oiticica, 1962.

PAULON, Simone; ROMAGNOLI, R. Pesquisa-intervenção e cartografia: melindres e meandros metodológicos. Estudos e Pesquisas em Psicologia, Rio de Janeiro, UERJ, n.1, p.85-102, jan./abr., 2010.

3 Tomamos este conceito como referência por ser uma das pistas de produção das ações da escola em que atuamos. 


\section{Fernando Yonezawa}

Doutor em Ciências pela Universidade de São Paulo, pós-doutorando junto ao Programa de PósGraduação em Psicologia Institucional da Universidade Federal do Espírito Santo.

E-mail: fefoyo@yahoo.com.br

Currículo: http://lattes.cnpq.br/3287085280527292

\section{Márcia Cuevas}

Doutora em Educação pela Universidade Federal do Espírito Santo, professora do Departamento de Psicologia da Universidade Federal do Espírito Santo.

E-mail: marcia.roxana@hotmail.com

Currículo: http://lattes.cnpq.br/6390983627032475

Recebido em 01 de fevereiro de 2017 Aceito em 30 de abril de 2017 